a STAC 4V74 exhibit

\title{
The Gubash Project
}

installation at Rodman Hall, St. Catharines

\author{
Artistic Contribution from \\ Maja Srndic (Research Assistant)
}

Oct 2011 
I become four things but remain one, or am I five, six, or seven? Or more? Am I a color, too? A shape? A bird? Yes, that must be me also! The letters, the sky, seeping into all without being definite. How nice!

But, how many eyes do I have? Ears, mouths, heads, lungs, noses? Branches, roots, bricks, edges, legs? Atoms? How do I move, sway, fly, rise out of the ground, exist as a color?

I only recall growing the tree out of fire, my nerves flourishing as they wait for foliage. Who knows how long that will take. I've been here for a long time...feels like a year. Roots spread underneath, clamping damp earth, such delicate handshakes, friendly worms roam about, but no leaves. How desolate and complete this place can be! Yestermorrownight, I decided to breathe sky into soft pink clouds. Hooooooooooooooooooo...Just like that. Cotton candy moves with licks of rain, trickling melting sugars nourishing my kin: the trees! Aren't they lovely? So fragile, so frail...my lovely silent cousins.

It's lonely here I tell you.

The bird that looks like a seagull is really a plastic bag: my guilty conscience. Pure, oh so pure, and just as conniving. It won't decompose for another, I don't know how many years, and refuses to take flight. So, I listen to its rustles, to its cracks, its holiness. As it skins me bare. It tells me I was sent here because I erred. I don't remember what I did. I was only looking for life. My seagull says otherwise; I did something wrong. But I made all you see right now, and I did it while I was lazying about. Imagine what would happen if I were productive! What beauty I made! My seagull doesn't hear my defence. No! My seagull doesn't listen. So, you must know how hard it is...having no one to talk to. Occasionally, I hum a tune. The rhythmic limbs of my rain: dum dum dummmm. Seldom, I hear ownerless vacant echoes; unoccupied; symphonies of an empty body. . . . . . . . . . Alienated from my own chords, I open my mouth and a foreign voice says: Come to my land, inhabit my land, join me, be my companion! Loneliness. No one is compelled by the contours of my country...

Strange, now I hear voices, voices like never before, armed cotton candied angels summon me to join their orders, as they file into art galleries, but I don't want to leave. Rain soaks my bones,

STAC 4V74: Contemporary Phototextuality The Gubash Project: Maja Srndic (Research Assistant) Brock University. Oct 2011 
steeps my wings to a cold of yellow green. I become a framed frozen image that movingly lingers between blinking intervals of your distracted eyelids...but I hope you listened and heard my silence: i am so many more!

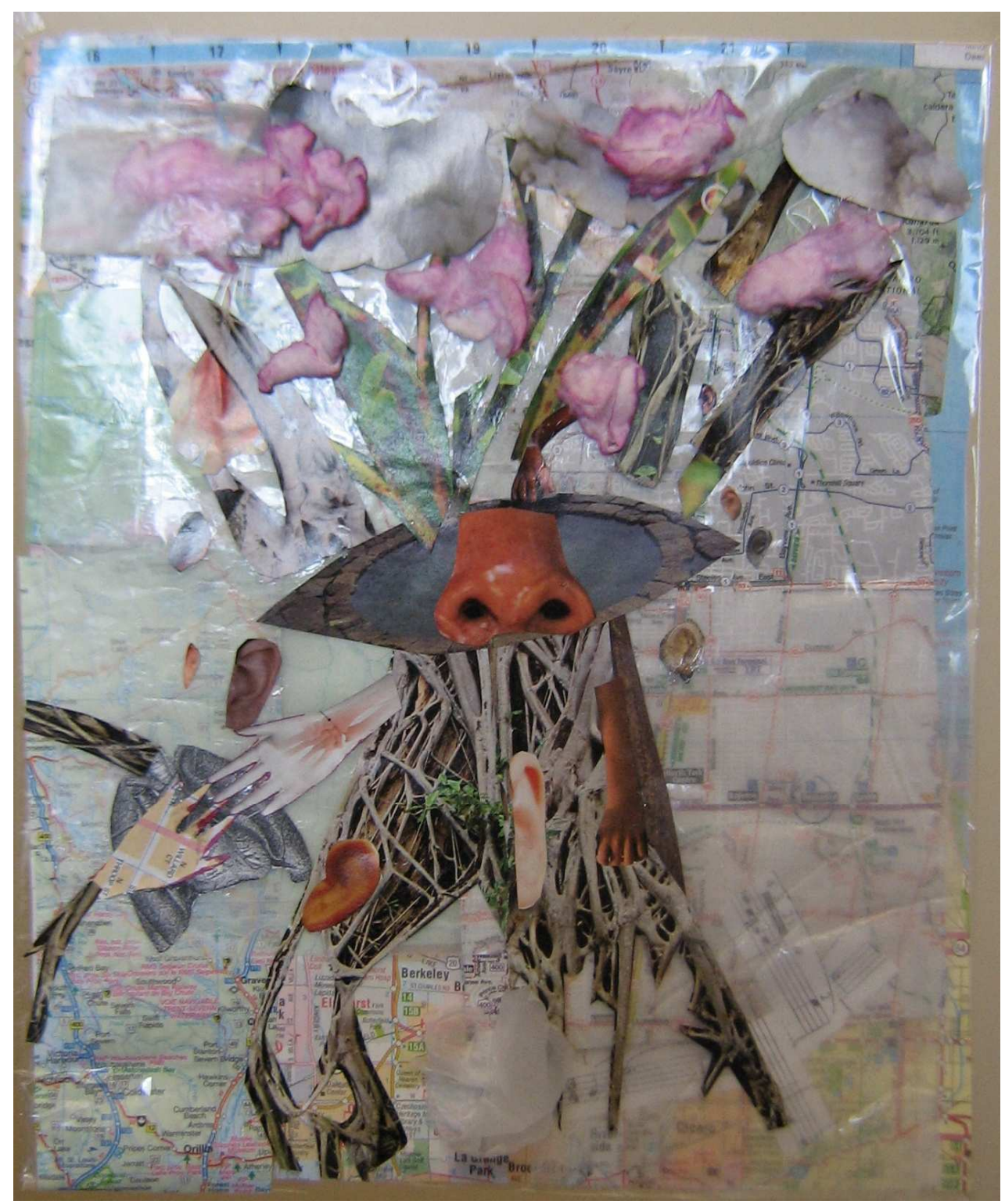

Collage. Mixed media. 8.5 x 11

Text and Collage by Maja Srndic

STAC 4V74: Contemporary Phototextuality The Gubash Project: Maja Srndic (Research Assistant) Brock University. Oct 2011 